American Journal of Agricultural and Biological Sciences 2 (2): 54-61, 2007

ISSN 1557-4989

(C) 2007 Science Publications

\title{
Control of Anthracnose Caused by Colletotrichum musae on Curcuma alismatifolia Gagnep. Using Antagonistic Bacillus spp.
}

\author{
${ }^{1}$ Supuk Mahadtanapuk, ${ }^{2}$ Mondhon Sanguansermsri, ${ }^{3}$ Robert W. Cutler, \\ ${ }^{4}$ Vicha Sardsud and ${ }^{5}$ Somboon Anuntalabhochai \\ ${ }^{1}$ School of Agriculture Natural Resources and Enviroment, Tumbol Maeka, \\ Naresuan University Phayao, Muang, Phayao, 56000 Thailand \\ ${ }^{2}$ Faculty of Pharmaceutical Sciences, Phitsanulok \\ Naresuan University Phitsanulok, 65000 Thailand \\ ${ }^{3}$ Bard College, Annandale-on-Hudson, New York, 12504 USA \\ ${ }^{4}$ Department of Plant Pathology, Faculty of Agriculture, \\ Chiang Mai University, Chiang Mai, 50200 Thailand \\ ${ }^{5}$ Department of Biology, Faculty of Science, \\ Chiang Mai University, Chiang Mai, 50200 Thailand
}

\begin{abstract}
Over 400 bacterial strains, isolated from leaf surfaces of Curcuma alismatifolia Gagnep. and hot springs in the Chiang Mai province of northern Thailand, were screened in vitro for antagonistic activity against Colletotrichum musae, an anthracnose fungus. Three isolates provided greater than $75 \%$ growth inhibition of the fungus in vitro and were identified as Bacillus licheniformis, $B$. amyloliquefaciens and B. subtilis. Using in planta tests, B. amyloliquefaciens and B. subtilis were shown to efficiently colonize the curcuma bracts, provide a statistically significant growth suppression of $C$. musae over that of B. licheniformis, and all three isolates could provide $100 \%$ inhibition of conidial fungal germination. When $B$. licheniformis was co-inoculated in combination with either of the other two bacteria, the ability of $B$. amyloliquefaciens and B. subtilis to suppress the fungal disease was dramatically reduced. Both B. amyloliquefaciens and B. subtilis were found to contain an isoform of iturin A with antifungal activity against $C$. musae. As a preventative measure to control the spread of $C$. musae and reduce the severity of fungal infections, B. amyloliquefaciens could be used to inoculate curcuma flowers cost effectively and reduce the need for the toxic synthetic fungicides currently in use.
\end{abstract}

Key words: Antagonistic bacteria, Colletotrichum musae, Curcuma alismatifolia Gagnep., Bacillus, iturin, fungicide alternative

\section{INTRODUCTION}

Curcuma (Curcuma alismatifolia Gagnep.), a species of the genus Zingiberaceae, is a decorative flower with highly variable shapes and bract colors that is an ornamental of significant economic importance for Thailand since it is regularly exported to many countries around the world including Japan, the U.S.A., the Netherlands and New Zealand. The highest quality curcuma variety, commonly called Siam Tulip, originates from South East Asia, and is regularly beset by anthracnose caused by Colletotrichum sp. resulting in a significant loss in production ${ }^{[1]}$. In fact, Anthracnose caused by $C$. musae has been cited as the single most serious disease of tropical plants worldwide and is the predominant pathogen of curcuma within Thailand ${ }^{[2]}$. Symptoms of anthracnose include an initial pinpoint water-soaked spotting of the curcuma flower. These spots then enlarge to approximately $3 \mathrm{~mm}$ in diameter and are light tan in the center with raised dark borders. On plants ready to transplant, large brown cankers can develop on the stems, and fruiting bodies called acervuli are present in affected areas. These acervuli produce pink spore masses and may have black bristle-like appendages called setae. Conidia can present as cylindrical to oblong protrusions while the mature spines show a standard sticklike form, which erupts over the outer epidermal cell wall of the host.

The current method to protect against this disease has been through the application of synthetic fungicides, but alternative methods to combat this disease could potentially be less harmful to human health and the environment ${ }^{[3]}$, and one such method has already achieved considerable success utilizing antagonism $^{[4,5]}$. Antagonistic biocontrol involves the

Corresponding Author: Robert W. Cutler, Department of Biology, Bard College, Annandale-on-Hudson, New York, 12504 USA 
use of naturally occurring nonpathogenic microorganisms that are able to reduce the activity of plant pathogens and thereby suppress diseases. Antagonistic microorganisms can complete with pathogens for nutrients, inhibit pathogen multiplication by secreting antibiotics or toxins, or reduce pathogen population through hyperparasitism. Moreover, some of these microorganisms can induce generalized resistance in plants, which enables the plant hosts to better defend themselves against pathogens ${ }^{[6]}$.

As a general method, biocontrol using antagonistic bacteria has been successfully demonstrated in a number of plant species. For example, bacterial isolates from the surface of banana fruits exhibited an antagonistic ability to suppress anthracnose disease caused by $C$. musa ${ }^{[7]}$. Other antagonistic bacteria such as Pseudomonas fluorescens, B. subtilis and $B$. megatherium were shown to control agents of the major cotton diseases, Xanthomonas campestris $p v$. malvacearum, Rhizoctonia solani, Fusarium vasinfectum and Verticillium dahliae ${ }^{[8]}$. Three bacterial strains $B$. subtilis, $B$. cereus and Pseudomonas corrugata were shown to control, Gaeumannomyces graminis var tritici which causes take-all disease, and rhizoctonia root rot caused by Rhizoctonia solani on wheat seedlings ${ }^{[9]}$. Epiphytic bacteria isolated from apples, pears, and the surface of apple leaves showed antagonistic activity against Penicillium expansum (blue-mold), while Botrytis cinerea (gray-mold) was an effective biocontrol agent on apple fruits ${ }^{[10,11]}$. Finally, several Trichoderma species can control Colletotrichum sp. in Zizyphus jujuba and anthracnose in mangos was controlled by an isolate of yeasts ${ }^{[12]}$, but currently little is known about methods of biocontrol for anthracnose caused by C. musae in curcuma.

Since the Bacillus genus includes some species which are known to be endophytically active ${ }^{[13,14]}$, it is likely that their endophytic ability could play a key role in the biocontrol of pathogens such as $C$, musae. Although antibiotic production by some bacteria including Bacillus spp. has been shown to play a major role in disease suppression ${ }^{[15,16,17,18]}$, only a few antibiotics have been isolated and identified for their role in biological control ${ }^{[19,20]}$. Specifically two species, B. subtilis and B. amyloliquefaciens were reported effective for the control of plant pathogens ${ }^{[21,22]}$, due to the presence of iturin a cyclic lipo-polypeptide reported to have antibacterial activity against a large variety of yeasts and fungi ${ }^{[23]}$. Due to the possible role of bacterial production of antibiotics in disease suppression, iturin could have considerable importance for pathogenic control in crop production, though not as a commercially produced substance since iturin is prohibitively expensive. The objective of this research was to investigate the biocontrol potential of antagonistic bacteria against anthracnose of curcuma bract to preserve the value of these cut flowers as ornamentals, and to reduce the dependence on toxic fungicides currently required to combat this disease.

\section{MATERIALS AND METHODS}

Plant material: The Curcuma alismatifolia Gagnep. (Chiang Mai Pink cultivar) used in this study was kindly provided by the Chiang Rai Horticulture Research Center, Chiang Rai province, Thailand. The flowers were cultivated individually from bulbs in a greenhouse until the plants reached the young bud stage. At full growth (28 days from initial budding) flowers were chosen for analysis.

Media and Culture Conditions: The fungal strain $C$. musae used in this study was initially collected as diseased tissues on Chiang Mai Pink curcuma from a private orchard in the Chiang Mai province. After being examined and identified using microscopy, the fungus was isolated for subsequent reinfection, and sequencing to identify the fungal species name. The curcuma bract was stored at $4^{\circ} \mathrm{C}$ and was routinely subcultured onto potato dextrose agar (PDA). Conidial induction of $C$. musae was performed in nutrient yeast dextrose agar (NYDA) media. All other bacterial strains were cultured on slants of Luria-Bertani (LB) at $4^{\circ} \mathrm{C}$ for further study.

Isolation and identification of antagonistic bacteria: Two independent sources were chosen to screen for antagonistic bacteria: epiphytic bacteria from curcuma leaf surfaces and thermo-tolerant bacteria previously isolated from the Sunkampaeng hot springs with temperatures over $90{ }^{\circ} \mathrm{C}$ in the Chiang Mai Province (unpublished collection). The hot springs bacteria were chosen since heat tolerant bacteria would be able to survive in the high temperature environment required by the curcuma flower and this resource was readily available. Ideally the bacteria would also be able to effectively use the curcuma plant as a host without causing damage to the flower. To optimize on this second trait, approximately 40 leaves $(5 \times 15 \mathrm{~cm}$ with an attached stalk) were harvested from different wild curcuma plants to be used as a source for the second bacteria group. Each of these leaves were spun twice in $200 \mathrm{ml}$ phosphate buffer, $\mathrm{pH} \mathrm{7}$, at $150 \mathrm{rpm}$ for $10 \mathrm{~min}$ and serial tenfold dilutions were made using the protocol from ${ }^{[11]}$. The first suspension was discharged while the second was plated on LB media $(0.1 \mathrm{ml}$ per plate) and incubated at $25^{\circ} \mathrm{C}$ for $24-48 \mathrm{hrs}$. Typical colonies of all isolates were streaked on LB and selected for storage at $4^{\circ} \mathrm{C}$. The isolates, which 
provided greater than $75 \%$ inhibition to fungal growth on three independent replicates, were selected and identified by conventional morphological and biochemical methods using the API50CHB kit (biomerieux ${ }^{\circledR)}$ (Institute of Science and technology, Thailand).

Antagonistic activity in vitro: The assay for antagonism was performed on PDA medium by a dual culture method as described by ${ }^{[24]}$. Briefly, the bacteria and pathogenic fungi were inoculated dually on PDA medium in petri dishes $2-2.5 \mathrm{~cm}$ apart. The inhibition of actively growing fungus by the bacteria on PDA plates was quantified as the distance of radial growth in centimeters. The cultures were incubated at room temperature, and growth of the fungus towards and away from the bacterium was allowed for 7 days after incubation for each of three replicates. Variation between replicates was generally found to be less than $2 \mathrm{~mm}$. The percentage inhibition of the growth of the fungi was calculated using the following formula:

$$
100 *\left(\mathrm{R}_{1}-\mathrm{R}_{2}\right) / \mathrm{R}_{1}
$$

where $R_{1}$ was the furthest radial distance growth of the fungus in the direction of the antagonist (a control value) and $R_{2}$ was the distance on a line between the inoculation positions of the fungus and bacteria ${ }^{[24]}$. Those antagonistic bacteria showing the highest percentage $(>75 \%)$ of fungal growth inhibition were selected for further suppression of conidial germination on Collectotricum musae and subsequent anthracnose response in planta.

Antagonistic inhibition on conidial germination of $\boldsymbol{C}$. musae: A mixture of $20 \mu \mathrm{l}$ of $C$. musae conidial suspension $\left(1 \times 10^{6}\right.$ cells $\left./ \mathrm{ml}\right)$ and $20 \mu$ of bacterial cell cultures was formed at increasing concentrations $\left(1 \times 10^{8}, 2 \times 10^{8}, 3 \times 10^{8}\right.$ and $\left.4 \times 10^{8} \mathrm{CFU} / \mathrm{ml}\right)$. The mixture was pipetted onto clean glass slides as a $0.5 \mathrm{~cm}$ diameter membrane. The slides were then incubated in moist chambers for six and a half hours using three replicate slides for each fungal isolate. At the end of the incubation period, a drop of lactophenol was added to each slide to arrest germination within the drop. Germination in this context was defined as a germ tube that had developed longer than half of the cell length. The percent germination in each fungal isolate was determined by counting 100 conidia from each isolate under the microscope and determining the proportion that had germinated.

Detection of Antagonistic activities in planta: The flower bract of 28 day-old, greenhouse grown curcuma plants was used for the in planta assay. Initially, each leaf was cleaned with $70 \%$ ethyl alcohol to form a surface sterile flower for the microorganisms. On the order of $2 \times 10^{8} \mathrm{CFU} / \mathrm{ml}$ (were added with $0.001 \%$ tween 20) of bacterial cells and $10^{7}$ cells $/ \mathrm{ml}$. of C. musae each were prepared for the test. The curcuma bracts were each wounded in three regions with a total of ten pinpricks using the technique described by ${ }^{[25]}$. Using a fungal cell suspension at a ratio of 1:1 with the bacterial species of interest, a $40 \mu \mathrm{l}$ aliquot of this suspension was inoculated into the wound. The two controls contained wounded bract with and without inoculation by the fungus cell suspension. The development of spot lesions was recorded daily during the 10 days of the experiment where the total number of infected leaves was recorded to determine the disease incidence as the percentage of leaves infected. In all treatments, the bracts were wrapped with a transparent plastic bag after inoculation and secured within the greenhouse to minimize coinfection by unknown bacteria. Each treatment was run with 3 replicates in which twenty curcuma bracts were used for each replicate.

Population dynamics of antagonistic bacteria: After incubation, the population of each bacterial species was estimated every 5 days using three flower bracts for each treatment. Wounded tissue was removed with a cork borer $(1 \mathrm{~cm}$ in diameter) and ground with mortar and pestle in $1 \mathrm{ml}$ of $0.05 \mathrm{M}$ phosphate buffer $(\mathrm{pH} 7)$ as detailed in ${ }^{[26]}$. Serial tenfold dilutions were made and $0.1 \mathrm{ml}$ of each dilution was spread on LB plates. The plates were incubated at $25^{\circ} \mathrm{C}$ for $48 \mathrm{hr}$ and the colony sizes quantified as a measure of the initial concentration of the bacteria.

Assays for the presence of anti-fungal compounds: Single cell cultures were inoculated into a $500 \mathrm{ml}$ flask containing $100 \mathrm{ml} \mathrm{LB}$ media, and the flasks were agitated on a rotary shaker at $120 \mathrm{rpm} / \mathrm{min}$ for $12 \mathrm{~h}$. at $37^{\circ} \mathrm{C}$. These cultures were then transferred to fresh flasks containing $100 \mathrm{ml}$ LB media and incubated under the same conditions for another $36 \mathrm{hrs}$. To remove the cells, the culture was centrifuged at $10,500 \mathrm{~g}$ for 15 min, then supernatant was saturated with solid ammonium sulfate to $65 \%(\mathrm{w} / \mathrm{v})$ and allowed to precipitate in an ice-bath. The precipitate was collected, dissolved in TE buffer $(0.01 \mathrm{M}$ Tris- $\mathrm{HCl} \mathrm{pH} 7.5+0.001$ $\mathrm{M}$ EDTA) and $10 \mu \mathrm{l}$ of the re-suspension of each bacterial species was spotted onto $7 \times 20 \mathrm{~cm}$ chromatograph paper. A commercially available source of iturin A (1 $1 \mu \mathrm{g}$; Sigma,U.S.A.) was used as a control to compare the bacterial isolate against. The paper was developed by using chloroform-methanol-water $(65: 25: 4)$ as the solvent system as described in $^{[27,28]}$. After separation, the chromatography paper was transferred and placed in an assayed PDA box $(7 \times 20$ $\mathrm{cm}$ ), containing $1 \times 10^{6}$ conidial $/ \mathrm{ml}$ of C. musae, and 
kept for one hour, after which the paper was taken away. Subsequently, the assayed PDA plates were incubated at room temperature until clear zones were observed (generally about 3 days for each of the three replicates). The clear or inhibitory zones of antifungal growth from each antagonist were measured and recorded as $\mathrm{R}_{\mathrm{f}}$ values in comparison to the commercial iturin A (Sigma, U.S.A.).

To further verify the presence of an isoform of iturin, human erythrocytes were prepared as described by $^{[29]}$ and in each assay $0.9 \mathrm{ml}$ of bacterial supernatant (O.D. of 2.0-2.25 at $560 \mathrm{~nm}$.) was added to $0.1 \mathrm{ml}$ of the erythrocyte suspension. Serial concentrations of iturin $\mathrm{A}$ of $2,4,6,8$, and $10 \mu \mathrm{g}$ were added to the same volume of erythrocyte suspension as equal volume and the final volume was adjusted to $1 \mathrm{ml}$ with $\mathrm{LB}$, (LB was used for control so that the final suspension contained $2.5 \times 10^{6}$ cells $/ \mathrm{ml}$ ). Subsequently the erythrocyte was incubated at $37^{\circ} \mathrm{C}$ for $30 \mathrm{~min}$. and then centrifuged.

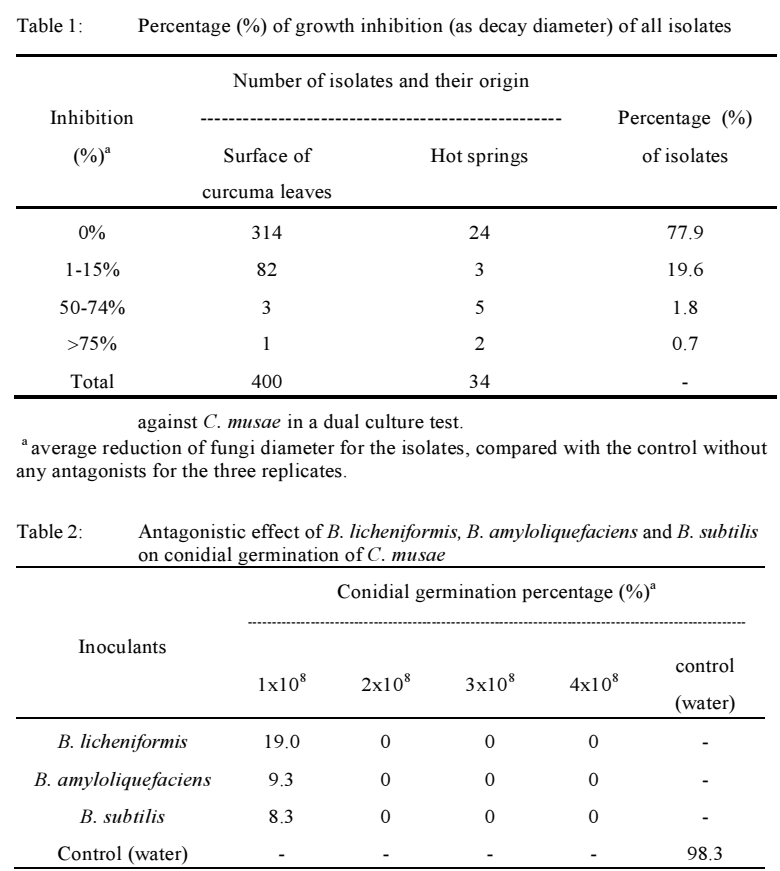

${ }^{\text {a }}$ average of the three C. musae germination experiments.

\section{RESULTS}

Antagonistic activity in vitro: Four hundred isolates from the surface of curcuma leaves and 34 isolates from hot springs were screened for an antagonistic effect against C. musae using the dual culture method described previously. The growth inhibition of $C$. musae by all of the bacteria isolates was determined after a week of incubation and recorded as a decay diameter (Table 1). About $78 \%$ of all isolates exhibited absolutely no growth inhibition and only $2.5 \%$ of the isolates provided inhibition greater than $50 \%$. Two isolates from the hot spring and one from the leaf surfaces reduced the growth diameter of the fungus by more than $75 \%$. The three isolates with the highest percentage of growth inhibition (Figure 1) were identified as B. licheniformis, B. amyloliquefaciens and $B$. subtilis by conventional morphological and biochemical methods (identification provided by the Institute of Science and Technology, Thailand) and were selected to interact (control) against C. musae in planta.

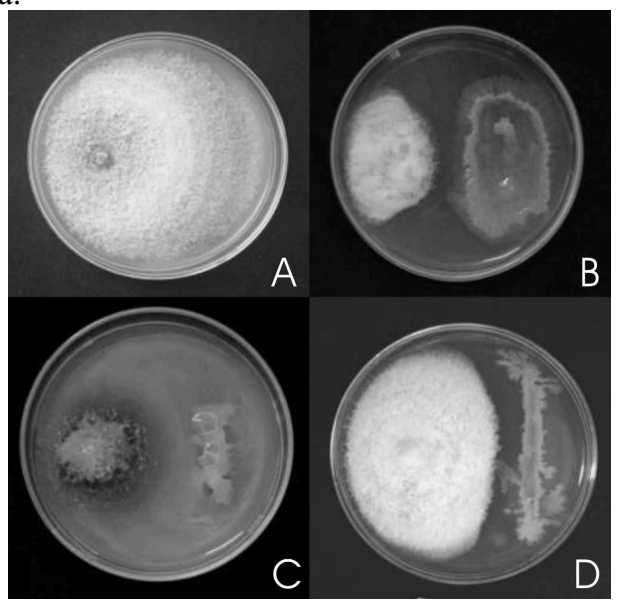

Fig. 1: The highest percentage inhibition of antagonistic bacteria on a dual culture testing. A: control, B: B. licheniformis, C: B. amyloliquefaciens, and D: B. subtilis.

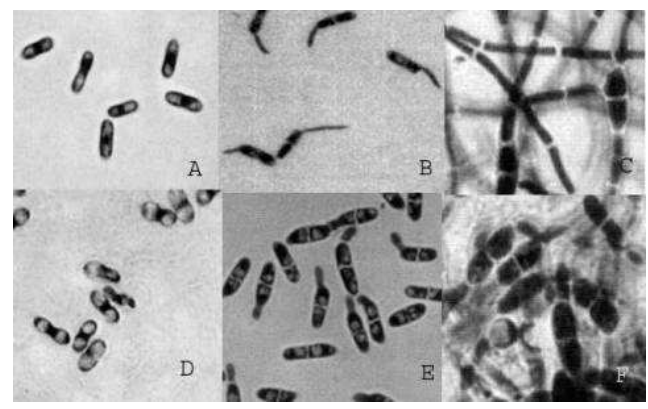

Fig. 2: $\quad$ Phenotypic appearance of $C$. musae shown with the tested antagonistic bacteria. A,B,C : normal conidial appearance, germination of conidial initially, and at $24 \mathrm{hr}$. (control). D,E,F: the swelling of conidial, swelling of germ tubes of conidial initially, and the short hyphal cells seen after 24 hr. Tested with the antagonistic bacteria (B. licheniformis, B. amyloliquefaciens and B. subtilis).

Antagonistic effects on conidial germination of $\boldsymbol{C}$. musae: To test the action of the three Bacilli species on the germination of $C$. musae, cell suspensions (at concentrations of $1 \times 10^{8}, 2 \times 10^{8}, 3 \times 10^{8}$ and $4 \times 10^{8}$ $\mathrm{CFU} / \mathrm{ml}$ ) from all three species (B. licheniformis, $B$. amyloliquefaciens and B. subtilis ) were tested against 
C. musae as described previously. For concentrations of $2 \times 10^{8}$ and greater, all three species showed an absolute inhibitory effect $(0 \%)$ on conidia germination in comparison to the control $(98 \%)$. Even at the lowest concentration of $1 \times 10^{8}$, overall germination levels were reduced to less than $20 \%$ for all three bacteria, and distinct morphological changes such as swelling of the conidia and the germ tubes were easily visualized (Figure 2).

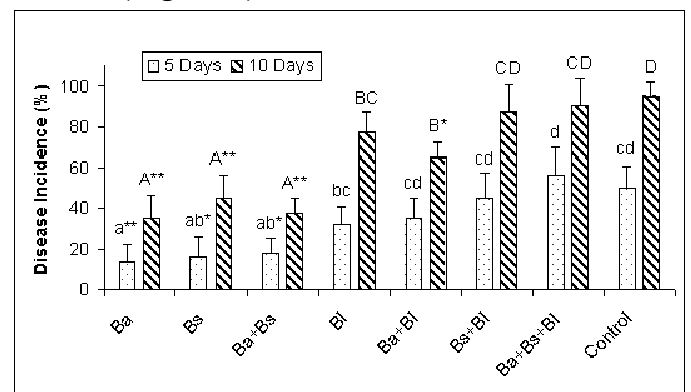

Fig. 3: Phenotypic appearance of C. musae shown with the tested antagonistic bacteria. A,B,C : normal conidial appearance, germination of conidial initially, and at $24 \mathrm{hr}$. (control).

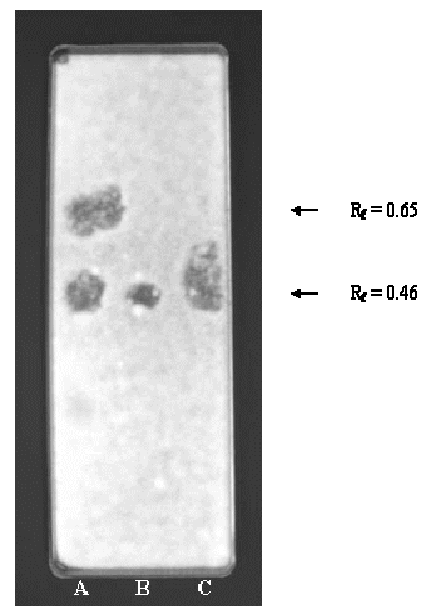

Fig.4 : Inhibition zones against $C$. musae from the crude extraction of A: B. subtillis, B: Iturin A, and C: B. amyloliquefaciens

Antagonistic activity in planta: The three bacteria, B. licheniformis, B. amyloliquefaciens and B. subtilis shown to inhibit growth of the fungus in vitro were tested singly and in combination against C. musae in planta using the wound prick technique described previously. At five and ten days, the average disease incidence and standard deviation for each combination of bacterial treatment was recorded for the three replicates of twenty plants in each run. Individually, over the 10-day growth period, B. amyloliquefacien showed the greatest degree of fungal growth inhibition in planta, followed by $B$. subtilis and then $B$. licheniformis as summarized in Figure 3. The combination of $B$. subtilis and B. amyloliquefacien provided essentially identical growth inhibition as that found with either species alone. When pairs of species were concurrently tested for fungal growth inhibition, an inhibitory effect between $B$. licheniformis and the other two species was found that cancelled the fungal growth reduction found individually. There was no statistically significant difference between fungal growth alone and fungal growth with all three species present. So using the wound prick technique, the highest levels of disease suppression occurred using $B$. amyloliquefacien and B. subtilis in combination and alone, with $B$. licheniformis just barely significantly different from the control at 10 days as shown in Figure 3.

Population dynamics of antagonistic bacteria: The Bacillus spp population dynamics of the antagonistic effect in planta was tested on bracts of prick-wounded curcuma with a $20 \mu \mathrm{l}$ volume suspension of each bacteria $\left(2 \times 10^{8} \mathrm{CFU} / \mathrm{ml}\right)$. The populations of two bacterial strains (B. amyloliquefaciens and B. subtilis) first multiplied rapidly in the bract wounds reaching a maximum population on day 10 and then declined gradually until day 15 . The overall population sizes of these two species were increased over 1000 -fold and 300 -fold, then dropped back to only 100 -fold of the original population after 15 days. The population of $B$. licheniformis showed a markedly reduced growth curve in which the population only initially increased 3 -fold to maximum at 5 days and then steadily declined.

Assay for an anti-fungal compound through haemolytic activity and paper chromatograph: A candidate compound known to have anti-fungal properties as well as the ability to haemolyze human erythrocytes is the cyclic lipo-polypeptide antibiotic iturin $^{[29]}$. To verify the presence of iturin in the supernatant of the three bacteria, supernatant from each species was tested against human erythrocytes in LB and compared at various concentrations with a commercially available antibiotic, iturin A (Sigma, USA). A $0.9 \mathrm{ml}$ supernatant from each bacteria culture was mixed with $2.5 \times 10^{6}$ cells $/ \mathrm{ml}$ of the erythrocytes and the presence of released hemoglobin in the suspension indicated the success of the hemolytic activity. Haemolytic activity was found to be present for B. amyloliquefaciens and B. subtilis but was absent for $B$. licheniformis, where the presence of hemoglobin was further verified by the measurement of a strong absorbance band at $540 \mathrm{~nm}$.

Since B. amyloliquefaciens and B. subtilis showed haemolytic activity (data not shown), provided an improved degree of growth inhibition to C. musae over 
B. licheniformis, and could thrive in planta, these two species were further investigated for the mechanism of their antagonistic activity. Preliminary characterization of the antifungal compound from the crude extract of both bacteria was determined by paper chromatography as described previously. After 3 days, the chromatogram of the extract from B. subtilis was separated into two biologically active bands at $R_{\mathrm{f}}$ values of 0.46 and 0.65 respectively, while in $B$. amyloliquefaciens a single band was found at an $\mathrm{R}_{\mathrm{f}}$ value of 0.46 . These $R_{f}$ values were determined by the clear zone in the PDA plate containing Colletotrichum's conidia and were equivalent to the $\mathrm{R}_{\mathrm{f}}$ value of Iturin alone (Figure 4).

\section{DISCUSSION}

After an initial screening of over 430 bacterial isolates from two different environments, the in vitro growth of $C$. musae was found to be markedly suppressed by three candidate bacterial species: B. licheniformis and $B$. amyloliquefaciens from hot springs and $B$. subtilis found residing on curcuma leaves. Out of the $430+$ bacterial species screened for in vitro growth suppression of the fungus, these three species exhibited the highest level of fungal growth inhibition (over $75 \%$ ) and at concentrations over $2 \times 10^{8} \mathrm{CFU} / \mathrm{ml}$ provided an absolute inhibitory effect on the germination of this fungus. Therefore assuming that sufficient levels of the bacteria could be induced to colonize the curcuma plants, the Bacillus species described here could have the potential to effectively treat and stop the spread of fungal infections by C. musae.

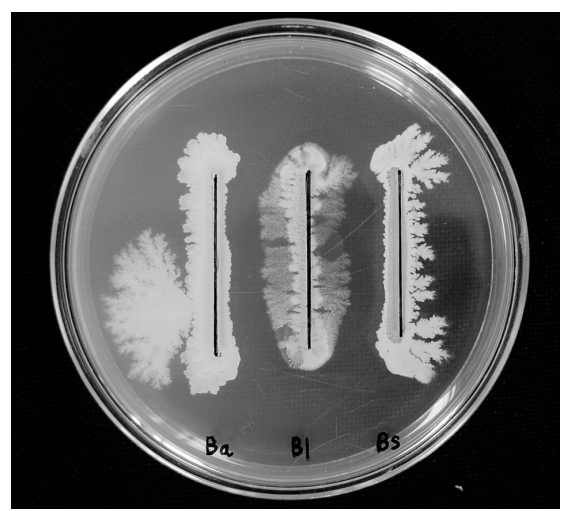

Fig. 5: A dual culture test showing growth suppression of $B$. amyloliquefaciens (Ba), B. subtilis $\quad(\mathrm{Bs})$ by B. licheniformis $(\mathrm{Bl})$.

The population dynamics of the growth of these bacteria in planta showed that the populations of $B$. amyloliquefaciens and B. subtilis increased rapidly two to three orders of magnitude until 10 days, while $B$. licheniformis decreased about 10-fold over the same time. Since B. licheniformis was unable to thrive in planta, it would most likely be unable to achieve sufficient concentrations to provide effective biocontrol. In addition, when the fungus was inoculated in combination with $B$. licheniformis and either of the other two bacteria, disease incidence suppression was dramatically reduced. This could be due in part to an antibacterial compound in $B$. licheniformis that inhibited the growth of the other two species thereby reducing the amount of antifungal substance produced. Figure 5 shows the growth inhibition of B. amyloliquefaciens and B. subtilis by $B$. licheniformis when grown in close proximity. Due to the overall unsuitability of $B$. licheniformis, further attempts to characterize the antifungal compounds were limited to $B$. amyloliquefaciens and $B$. subtilis.

A number of reports have shown that different strains of both B. amyloliquefaciens and B. subtilis contain multiple isoforms of the cyclic lipopolypetide antibiotic iturin ${ }^{[30,31]}$. The mechanism for the action of iturin $\mathrm{A}$ is to form pores which can aggregate in the cytoplasmic membrane as the concentration of iturin increases leading to conductance channels and cellular leakage ${ }^{[32]}$. Since different isoforms of this same compound can have dramatically different effects, multiple studies have shown that effective biocontrol agents must be optimized to suppress specific plant pathogens ${ }^{[11,22,26]}$. In this work, both of these strains were shown to have extra cellular metabolites with haemolytic activity and the presence of iturin was verified using a paper chromatography assay. Therefore at least one of the mechanisms involved in the anti-fungal function of this biocontrol system involves iturin A production by the antagonistic bacteria. Although the clear suppression by iturin A found on the PDA media suggests the commercially available substance could be a viable anti-fungal agent, iturin $\mathrm{A}$ is not a practical anti-fungal agent due to the high cost of this compound. Since B. subtilis contained a second clear zone in the paper chromatography results there is at least one additional substance in B. subtilis, which could be the object of future study to provide additional fungal growth inhibition.

In this study, the growth of $C$. musae was found to be $10 \mathrm{x}$ fold reduced in the presence of $B$. amyloliquefaciens and B. subtilis over no co-infection for the plants that were initially challenged with a heavy inoculation of C. musae. This suggests that plants colonized by these species of Bacilli before 
infection by $C$. musae may be able to inhibit the growth of the fungus before it is able to affect the commercial value of these cut flowers. Future investigations into the use of $B$. amyloliquefaciens and $B$. subtilis could examine different methods for inoculating plants at the most favorable stage of plant development and the best level of inoculum needed to obtain effective disease control for optimal antagonistic colonization.

Although the life cycle of $C$. musae in curcuma has not yet been studied, it is generally believed that both flower parts and the last bunch bract are important sources for the spread of $C$. musae through rain splash of the conidia, transport by insects, or aerial dissemination of ascospores. Further investigations into the primary vectors spreading Colletotrichum musae would provide additional insights into ways to reduce the economic impact of this disease. As a key species causing anthracnoses, C. musae is known to cause quiescent infections in other tropical fruits such as papaya $^{[33]}$, mango ${ }^{[34]}$, and the avocado ${ }^{[35]}$. This suggests that the presence of C. musae may be more widespread than is currently believed and that there may already be varieties of curcuma naturally resistant to the infection which could provide additional methods to combat this disease.

For the effective use of Bacillus as a biocontrol agent against $C$. musae on curcuma, either species $B$. amyloliquefaciens or $B$. subtilis in combination or alone could be used to inoculate the curcuma flowers, as long as there is no co-infection with $B$. licheniformis since this dramatically reduces the biocontrol effectiveness. For the development of a commercially viable biocontrol agent against $C$. musae, the overall best possibility is $B$. amyloliquefaciens because of its ability to absolutely suppress germination of the fungus, effectively colonize curcuma bracts and act as an effective antifungal agent. For less than 1 US dollar, a $20 \mathrm{ml}$ culture of starter bacteria could be grown overnight to provide greater than $2 \times 10^{10} \mathrm{CFU} / \mathrm{ml}$ of bacteria in 5 liters of solution. This concentration of bacteria could be diluted to 150 liters to provide an absolute inhibition of fungal germination in a $1600 \mathrm{~m}^{2}$ area which is the approximate size of a large curcuma plantation. By stopping the spread of the fungus and acting as an effective anti-fungal agent, the strain of $B$. amyloliquefaciens isolated in this study offers a strong candidate for effective and competitive biocontrol.

\section{ACKNOWLEDGMENTS}

This work was supported by Naresuan University and Bard College.

\section{REFERENCES}

1. Holland, K.P., 1999. Consumer Info. Available: http://www.kpholland.nl

2. Mahadtanapuk, S., 2005. Molecular Cloning of $c D N A$ Encoding ACC Synthase and Application of Antagonistic Bacteria for Disease Control in Curcuma alismatifolia Gagnep. Chiang Mai, Thailand: University of Chiang Mai, $\mathrm{PhD}$ thesis.

3. Tian, S. and Q. Fan, 2000. Biological technologies for controlling postharvest diseases of fruits and vegetables. - Chin. Bull. of Bot. 17: 193-203.

4. McLaughlin, R.J., C.L. Wilson, S. Droby, R. Ben-Arie and E. Chalutz, 1992. Biological control of postharvest diseases of grape, peach, and apple with yeasts Kloeckera apiculata and Candida guilliermondii. Plant Dis. 76: 470-473.

5. Wilson, C.L. and M.E. Wisniewki, 1989. Biological control of postharvest diseases of fruits and vegetables: An emerging technology. - Ann. Rev. of Phytopath. 27: 425-441.

6. Mukerji, K.G., B.P.Chamola and R.K. Upadhyay, 2000. Biotechnological approaches in biocontrol of plant pathogens. - Phytochem. 54: 445-446.

7. Postmaster, A., J. Kuo, K. Sivasithamparam, D.W. Turner, 1997. Interaction between Colletotrichum musae and antagonistic microorganisms on the surface of banana leaf discs. - Scient. Horti. 1: 113-125.

8. Safiyazov, J.S., R.N. Mannanov and R.K.Sattarova, 1995 The use of bacterial antagonists for the control of cotton diseases. - Field Crops Res. 43: 51-54.

9. Ryder, M.H., Z. Yan, T.E. Terrace, A.D. Rovira, W. Tang and R.L. Correll, 1998 Use of strains of bacillus isolated in China to suppress take-all and rhizoctonia root rot, and promote seedling growth of glasshousegrown wheat in Australian soils. - Soil Bio. and Biochem. 31: 19-29.

10. Janisiewicz, W.J. and N. Jeffers, 1997. Efficacy of commercial formulation of two bio-fungicides for control of blue mold and gray mold of apples in cold storage. - Crop Prot. 16: 629-633.

11. Vinas, I., J. Usall, N. Teixido and V. Sanchis, 1997. Biological control of major postharvest pathogens on apple with Candida sake. - J. of Food Microbio. 40: 9-16.

12. Sangchote, S. and M. Saoha, 1997. Control of Post-harvest Disease of Mango Using Yeasts. - Aciar Proc. 81: 108-112. 
13. Lilley, A.K., J.C. Fry, M.J. Bailey and M.J. Day, 1996. Comparison of aerobic heterophic taxa isolated from root domains of mature sugar beet. - FEMS Microbiol. Ecol. 21: 231242.

14. Mahaffee, W.F., and J.W. Kloepper, 1997. Temporal changes in the bacterial communities of soil, rhizosphere and endorhiza associated with field-grown cucumber (Cucumis sativus L.). - Microb. Ecol. 34: 210-223.

15. Cook, RJ., LS. Thomashow, B.M. Weller, D. Fujimoto, M. Mazzola, G and Bangera, D-S. Kim, 1995. Molecular mechanisms of defense by rhizobacteria against root disease. - Proc. of the Nat. Acad. of Sci. of the USA 92: 41974201.

16. Dowling, D.N. and F. O'Gara, 1994. Metabolites of Pseudomonas involved in the biocontrol of plant disease. - Trends in Biotechn. 12: 133-141.

17. Fravel, D.R., 1988. Role of antibiosis in the biocontrol of plant diseases. - Annu. Rev. of Phytopath. 26: 75-91.

18. Klich, M.A., K.S. Arthur, A.R. Lax and J.M. Bland, 1994. Iturin A: a potential new fungicide for stored grains. - Mycopathol. 127: 123-127.

19. Asaka, O. and M. Shoda, 1996. Biocontrol of Rhizoctonia solani damping-off of tomato with Bacillus subtilis RB14. - Appl. Environ. Microbio. 62: 4081-4085.

20. Gueldner, R.C., C.C. Reilly, P.L. Pusey, C.D. Costello, R.F. Arrendale, R.H. Cox, D.S. Himmelsbach, F.G. Crumley and H.G.Cutler, 1988. Isolation and identification of iturins as antifungal peptides in biological control of peach brown rot with Bacillus subtilis. - J. of Agri. and Food Chem. 36: 366-370.

21. Yu, G.Y. and J.B. Sinclair, 1997. Purification and identification of an antifungal peptide produced by a potential biocontrol agent Baclillus amyloliquefaciens B94. - Phytopath. 87: 8107.

22. Yoshida, S., A. Shirata and S. Hiradate, 2002. Ecological characteristic and biological control of mulberry anthracnose. - JARQ 36 (2): 89-95.

23. Besson, F., F. Peypoux, G. Michel and L. Delcambe, 1979. Antifungal activity upon Saccharomyces cerevisiae; inhibition of this antifungal baclillomycin $\mathrm{L}$ and of their derivatives; inhibition of this antifungal activity by lipid antagonists. - J. of Antibiot. 32: 828-833.
24. Skidmore, A.M. and C.H. Dickinson, 1976. Colony interaction and hyphal interference between Septoria nodorum and phyllop lane fungi. - Trans. Br. Mycol. Soc. 66: 57-64.

25. May, R., B. Volksch and G. Kampmann, 1997. Antagonistic activities of epiphytic bacteria from soybean leaves against Pseudomonas syringae pv. glycinea in vitro and in planta. - Microb. Evol. 34: 118-124.

26. Tian, S., Q. Fan, Y. Xu and H. Liu, 2002. Biocontrol efficacy of antagonist yeast to gray mold and blue mold on apples and pears in controlled atmospheres. - Plant Dis. 86: 848853.

27. Eshita, S.M., N.H. Rbberto, J.M. Beale, B.M. Mamiya and R.F. Workman, 1995. Bacillomycin $\mathrm{L}_{\mathrm{C}}$, a new antibiotic of the iturin group: isolation, structures, and antifungal activites of the congeners. J. of Antibiot. 48: 1240-1247.

28. Winkelmann, G., R.L. Allgaier and G. Jung, 1983. Iturin $A_{L}-a$ new long chain iturin $A$ possessing an unusual high content of $\mathrm{C}_{16}-\beta$ amino acids. - J. of Antibio. 36: 1451-1457.

29. Quentin, M.J., F. Besson, F. Peypoux and G. Michel, 1982. Action of peptidolipidic antibiotics of the iturin group on erythocytes. - Biochim. et Biophys. Acta 684: 207-211.

30. Hiradate, S., S. Yoshida, H. Sugie and H. Yada, 2002. Mulberry anthracnose antagonists (iturins) produced by Bacillus amyloliquefaciens RC-2. - Phytochem. 61: 693-698.

31. Tsuge, K., T. Akiyama and M. Shoda, 2001. Cloning, sequencing, and characterization of the iturin A operon. - J. of Bacter. 183: 62656273.

32. Maget-Dana, R., M. Ptak, F. Peypoux, and G. Michel, 1985. Poreforming properties of iturin A, a lipopeptide antibiotic. - Biochim. et Biophys. Acta 815: 405-409.

33. Dickman, MB. and A.M. Alvarez, 1983. Latent infection of papaya caused by Colletotrichum gloeosporioides. - Plant Dis. 67: 748-750.

34. Wardlaw, C.W. and R.E.D. Baker, 1939. Latent infections in tropical fruits. - Trop. Agri. 16: 275-286.

35. Benyamini, N. and M. Schiffmann-Nadel, 1972. Latent infection in avocado fruit due to Colletotrichum gloeosporioides. - Phytopath. 62: 592-595. 